\title{
Heat and mass transfer in a square microchannel with asymmetric heating
}

\author{
P. van Male ${ }^{\mathrm{a}}$, M.H.J.M. de Croon ${ }^{\mathrm{a}}$, R.M. Tiggelaar ${ }^{\mathrm{b}}$, A. van den Berg ${ }^{\mathrm{b}}$, \\ J.C. Schouten ${ }^{\mathrm{a}, *}$ \\ ${ }^{a}$ Laboratory of Chemical Reactor Engineering, Eindhoven University of Technology, P.O. Box 513, \\ 5600 MB Eindhoven, The Netherlands \\ ${ }^{\mathrm{b}} \mathrm{MESA}^{+}$Research Institute, University of Twente, P.O. Box 217, 7500 AE Enschede, The Netherlands
}

Received 2 September 2002; received in revised form 22 April 2003

\begin{abstract}
This paper describes the heat and mass transfer in a square microchannel that is heated from one side. This microchannel represents a reaction channel in a microreactor that is used to study the kinetics of the catalytic partial oxidation of methane. The microchannel is contained in a silicon wafer and is covered by a thin silicon sheet. At the top side of this sheet, heating elements are present which mimic the heat that is produced as a result of the exothermic chemical reaction. Correlations for Nusselt and Sherwood numbers as a function of the Graetz number are derived for laminar and plug flow conditions. These correlations describe the heat and mass transport at the covering top sheet of the microchannel as well as at its side and bottom walls. By means of computational fluid dynamic simulations, the laminar flow is studied. To determine an approximate laminar flow Nusselt correlation, the heat transport was solved analytically for plug flow conditions to describe the influence of changes in the thermal boundaries of the system. The laminar flow case is experimentally validated by measuring the actual temperature distribution in a $500 \mu \mathrm{m}$ square, $3 \mathrm{~cm}$ long, microchannel that is covered by a $1 \mu \mathrm{m}$ and by a $1.9 \mu \mathrm{m}$ thick silicon sheet with heating elements and temperature sensors on top. The Nusselt and Sherwood correlations can be used to readily quantify the heat and mass transport to support kinetic studies of catalytic reactions in this type of microreactor.
\end{abstract}

(c) 2003 Elsevier Ltd. All rights reserved.

\section{Introduction}

Microreactors have characteristic properties, like a high surface to volume ratio, small amounts of chemicals, laminar flow, high heat and mass transfer rates, and short residence times, that make these devices a research topic of high interest. Microstructured chemical reactors are proposed for various applications, such as smallscale production of hydrogen for fuel cells, intrinsic kinetic studies, catalyst screening, and fine-chemicals synthesis [1-3]. The work reported in this paper is part of a project in which a silicon-based microreactor for

\footnotetext{
${ }^{*}$ Corresponding author. Tel.: +31-40-247-2850; fax: +31-40244-6653.

E-mail address: j.c.schouten@tue.nl (J.C. Schouten).
}

catalytic partial oxidation of methane to hydrogen and carbon monoxide is developed. This exothermic reaction requires contact times in the order of milliseconds, and therefore a microreactor is very suitable as it typically has short residence times. The microreactor used (Fig. 1) is made in silicon at the MESA ${ }^{+}$Research Institute. The reactor has a square reaction channel with a hydraulic diameter of $500 \mu \mathrm{m}$ and a length of $3 \mathrm{~cm}$. The top wall of the channel is formed by a thin silicon sheet (thickness approximately $1-2 \mu \mathrm{m}$ ). This thin top layer will allow a good thermal contact between the catalyst beneath it, and the five heating wires and 12 temperature sensors on top of the sheet. The other three channel walls also consist of silicon. Due to the very high heat conductivity of silicon $\left(148 \mathrm{~W} \mathrm{~m}^{-1} \mathrm{~K}^{-1}\right.$ at $\left.300 \mathrm{~K}\right)$, these three walls will have an equal temperature. As they ensure rapid transfer of heat out of the reaction channel, their 


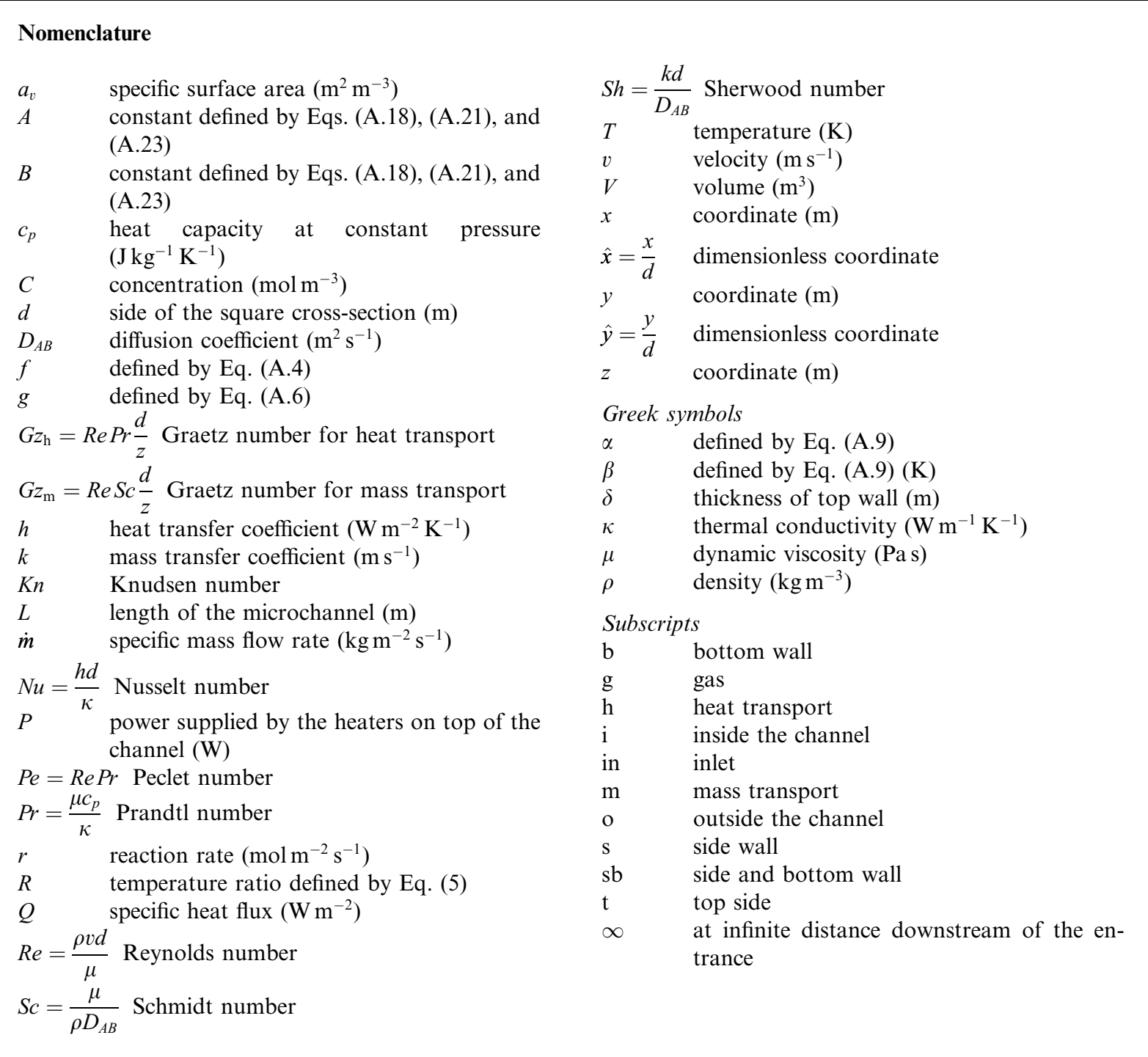

temperature will be lower than the mean temperature of the heated top side during steady state operation. The high rate of heat transfer will allow a good control of the reaction conditions inside the channel over a wide range of temperatures [1,4]. The temperature sensors on top of the channel allow to measure the catalyst temperature accurately, as the distance between the sensors and the catalyst (approximately $1-2 \mu \mathrm{m}$ ) is much shorter than the distance between the sensor and the heating wires (45 $\mu \mathrm{m})$. The heat and mass transport phenomena in the microchannel must be accurately known, to be able to determine the intrinsic kinetics of the catalytic reaction.

The present study focuses on the heat and mass transport inside the square microchannel. By means of computational fluid dynamic (CFD) simulations these transport phenomena can be quantified. However, these calculations are very time consuming and are therefore not suitable for general reactor design purposes and kinetic data treatment. For that reason, correlations that describe the dependencies of the Nusselt and Sherwood numbers along the channel axial coordinate are preferred. As the correlations are based on dimensionless numbers, they can also be applied when the dimensions of the square reaction channel change. The Nusselt correlation will be used to calculate the mean gas temperature along the channel and with the Sherwood correlation the mass transport coefficient will be calculated. When the channel diameter is small, rarefaction effects like velocity slip and temperature jump need to be considered [5-7]. The channel of our reactor is still large enough $(500 \mu \mathrm{m})$ to neglect these effects as the Knudsen number $\left(K n=1.6 \times 10^{-4}\right.$ for air at $\left.350 \mathrm{~K}\right)$ is less than 


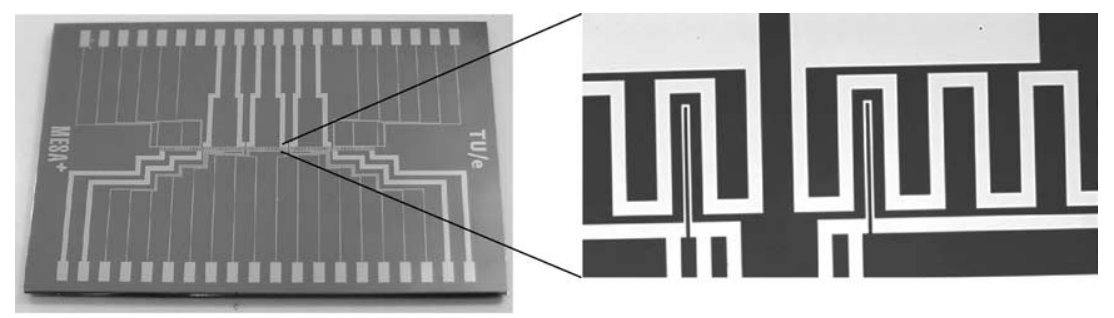

(a) Photo of microreactor

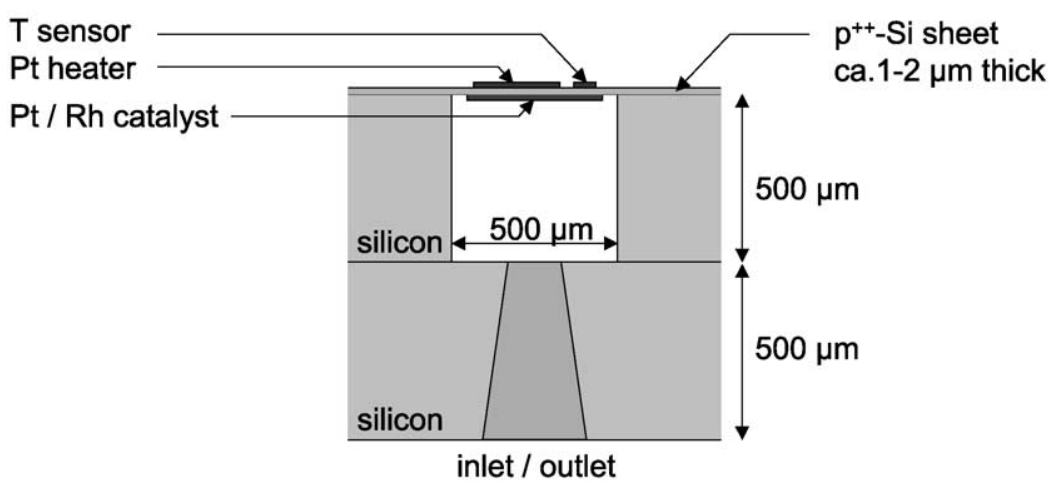

(b) Cross-section of the reactor

Fig. 1. (a) The left photo is of the microreactor $(30 \mathrm{~mm} \times 45 \mathrm{~mm})$; the gray lines are platinum wires. Near the long edge of the reactor, these wires end in pads for connections to a printed circuit board. In the middle of the reactor the platinum wires form five heaters and 12 temperature sensors. The heaters and temperature sensors lie on top of a silicon sheet, covering the reaction channel. The right photo is an enlargement of part of the heater and sensor structures. The thick meandering lines $(50 \mu \mathrm{m}$ wide $)$ are heater elements and the tiny loops $(10 \mu \mathrm{m}$ wide) are two temperature sensors. (b) Schematic representation of a cross-section of the reactor. The inlet and outlet of the square channel are situated on the reverse.

$10^{-3}$ and the continuum flow assumption is still valid. Although Nusselt and Sherwood correlations for many different combinations of boundary conditions can be found in literature for square and rectangular (micro) channels [8-11] the specific combinations used for our channel were not found. The boundary conditions of the channel are asymmetrical: the boundary condition of the top wall on the one side, and the bottom walls and the side walls of the channel at the other side are different. The heat is produced by an exothermic reaction at the top wall, which will therefore have a higher temperature as compared to the side and bottom walls. Also the mass transport is asymmetrical. The gas components will need to diffuse to the catalytic surface which is only present at the top wall of the channel.

\section{Heat and mass transport in a microchannel}

\subsection{CFD modelling and simulation}

To derive the mentioned Nusselt and Sherwood correlations, the specific heat flux $(Q)$ through the microchannel walls as well as the gas temperature distribution
$\left(T_{\mathrm{g}}\right)$ inside the microchannel is calculated with the CFD package FLUENT 5.5 [12]. FLUENT simultaneously solves the momentum, continuity, and energy equations by means of the control volume based technique. The control volumes are defined by means of the computational grid, describing the geometry of the microchannel. In Fig. 2 the coordinate system is shown. Because of the symmetry plane at $x=\frac{1}{2} d$, only half of the geometry is used to make a computational grid. The grid consists of $12 \times 16 \times 700$ grid points in the $(x, y, z)$ directions. The top wall of the channel is $1-2 \mu \mathrm{m}$ thick $(\delta)$ and $3 \mathrm{~cm}$ long $(L)$, giving an aspect ratio of 1:15000. This large aspect ratio would give a very dense mesh when the thin silicon sheet is incorporated in it. A dense mesh will result in long calculation time. Therefore the thin top sheet is considered as a heat conducting surface with power generation to take into account the power supplied by the heaters. Because silicon has a high heat conductivity, it is assumed that the temperature of the bottom $\left(T_{\mathrm{b}}\right)$ and side walls $\left(T_{\mathrm{s}}\right)$ of the microchannel are isothermal. In the simulations nitrogen gas is used as the gas phase with temperature dependent physical properties. In all simulations, the inlet gas temperature is $300 \mathrm{~K}$, the inlet gas velocity is $10 \mathrm{~m} / \mathrm{s}$ and enters the channel with an uniform 


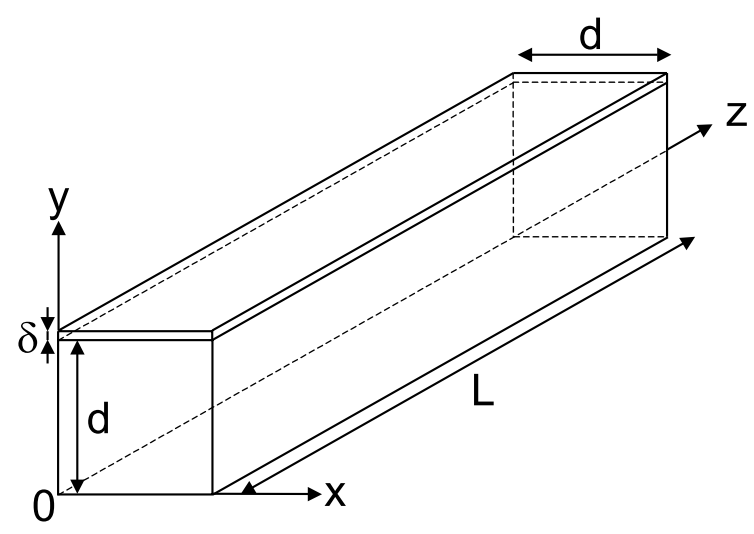

Fig. 2. Rectangular coordinate system used for the simulations and calculations of the microchannel. $\delta$ is the thickness of top wall of the channel, $d$ is the channel diameter, and $L$ is the channel length.

velocity profile. At the outlet the pressure is set at $1 \mathrm{~atm}$. Axial dispersion is taken into account in the FLUENT simulations although the Peclet number $(P e)$ is high enough $(P e>100)$ to neglect this effect. The flow regime inside the channel is laminar $(200<R e<500)$ because of the small diameter of the channel. With the CFD package FLUENT, the heat and mass transport are simulated inside the square microchannel. The laminar flow simulations are compared to the plug flow case in which an uniform distribution of the gas velocity at the cross-section of the channel exists. Analytical solutions for the plug flow case enable us to derive the Nusselt and Sherwood correlations for the laminar flow case.

The FLUENT simulations are verified to ensure the validity of the numerical analysis. The grid dependence of the results is examined by using different mesh sizes. The computational grid used for calculating the presented results gives grid independent results.

\subsection{Nusselt correlation for laminar flow}

With the use of FLUENT simulations, the heat transport at the channel walls is quantified. To be able to calculate the heat transport at the four walls, a subroutine has been written to extract the Nusselt number at a specific coordinate. The Nusselt number at each of the different walls is calculated using Eq. (1):

$N u_{i}=\frac{Q_{i} d}{\kappa_{i}\left(\bar{T}_{i}-\bar{T}_{\mathrm{g}}\right)}$

$N u_{i}$ is the Nusselt number at wall $i ; Q_{i}$, the specific heat flux at wall $i ; d$, the hydraulic diameter of the channel; $\kappa_{i}$, the thermal conductivity of the gas; $\bar{T}_{i}$, the mean temperature of wall $i$; and $\bar{T}_{\mathrm{g}}$, the bulk mean fluid temperature of the gas. $Q_{i}$ and $\bar{T}_{i}$ are calculated as an area weighted average. The Nusselt numbers at all four channel walls are needed to calculate the mean gas temperature inside the channel by means of iteration. From a heat balance over the microchannel it follows:

$\frac{\dot{m} d^{2}}{\kappa}\left(\frac{\mathrm{d} c_{p} \bar{T}_{\mathrm{g}}}{\mathrm{d} z}\right)=d a_{\mathrm{v}, \mathrm{t}} N u_{\mathrm{t}}\left(\bar{T}_{\mathrm{t}}-\bar{T}_{\mathrm{g}}\right)+d a_{\mathrm{v}, \mathrm{sb}} N u_{\mathrm{sb}}\left(T_{\mathrm{s}}-\bar{T}_{\mathrm{g}}\right)$

in which $\dot{m}$ is specific mass flow rate; $c_{p}$, the heat capacity; $a_{\mathrm{v}, \mathrm{t}}$ and $a_{\mathrm{v}, \mathrm{sb}}$, the specific surface areas of the top wall and of the side and bottom wall respectively; $N u_{\mathrm{t}}$, the Nusselt number at the top wall, and $N u_{\mathrm{sb}}$, the average Nusselt number at the side $\left(N u_{\mathrm{s}}\right)$ and bottom $\left(N u_{\mathrm{b}}\right)$ walls (Eq. (4)). Eq. (2) can be written as:

$\frac{\frac{1}{c_{p}}\left(\frac{\mathrm{d} c_{p} \bar{T}_{\mathrm{g}}}{\mathrm{d} G z_{\mathrm{h}}^{-1}}\right)}{1+\left(\frac{\mathrm{d} \ln R e P r}{\mathrm{~d} G z_{\mathrm{h}}^{-1}}\right)}=d a_{\mathrm{v}, \mathrm{t}} N u_{\mathrm{t}}\left(\bar{T}_{\mathrm{t}}-\bar{T}_{\mathrm{g}}\right)+d a_{\mathrm{v}, \mathrm{sb}} N u_{\mathrm{sb}}\left(T_{\mathrm{s}}-\bar{T}_{\mathrm{g}}\right)$

in which $G z_{\mathrm{h}}$ is the local Graetz number:

$G z_{\mathrm{h}}=\operatorname{RePr} \frac{d}{z} \quad$ and $\quad N u_{\mathrm{sb}}=\frac{2 N u_{\mathrm{s}}+N u_{\mathrm{b}}}{3}$

In Fig. 3(a) the Nusselt number at the top wall $\left(N u_{\mathrm{t}}\right)$ is plotted against the reciprocal Graetz number. In Fig. 3(b) the average Nusselt number at the side and bottom walls $\left(N u_{\mathrm{sb}}\right)$ is plotted against the reciprocal Graetz number. The temperature of the top wall is changed by varying the power $(P)$ on each of the five heaters. For the case when all walls are set at an equal temperature, it is found that $N u_{\mathrm{t}}=N u_{\mathrm{sb}}=2.98$ for $G z_{\mathrm{h}}^{-1}>0.1$ which is in agreement with the literature value [9].

From Fig. 3(a) it can be seen that when $T_{\mathrm{s}}=500 \mathrm{~K}$ and $P=0.5 \mathrm{~W}$, the Nusselt number shows a minimum at $G z_{\mathrm{h}}^{-1}=0.05$. This minimum is always found when the inlet temperature of the gas is below the temperature of the side walls. In literature [13], a minimum value for the Nusselt number has also been observed when heat transport is influenced by the wall heat conduction. It is reported that at low $G z_{\mathrm{h}}^{-1}$, the Nusselt number approaches the Nusselt number with an isothermal boundary condition. At high $G z_{\mathrm{h}}^{-1}$ the Nusselt number approaches the Nusselt number with a constant heat flux boundary condition. In Fig. 3, at small $G z_{\mathrm{h}}^{-1}$, the $N u_{\mathrm{t}}$ and $N u_{\text {sb }}$ are approximately equal to the value for the case that all four walls are at the same temperature. At high $G z_{\mathrm{h}}^{-1}$, the $N u_{\mathrm{t}}$ and $N u_{\mathrm{sb}}$ are approximately equal to the value for the situation when the side walls have the same temperature as the inlet temperature. To better understand the origin of this transition of $N u_{\mathrm{t}}$ and $N u_{\mathrm{sb}}$, as the heat transport develops along the reactor length, we solved the equations for plug flow inside the microchannel analytically (Appendix A.1). The transition of the Nusselt number at the top wall we found for the laminar flow case (Fig. 3) is also found at plug flow conditions (Fig. 7). From Eq. (A.14) it can be seen that 


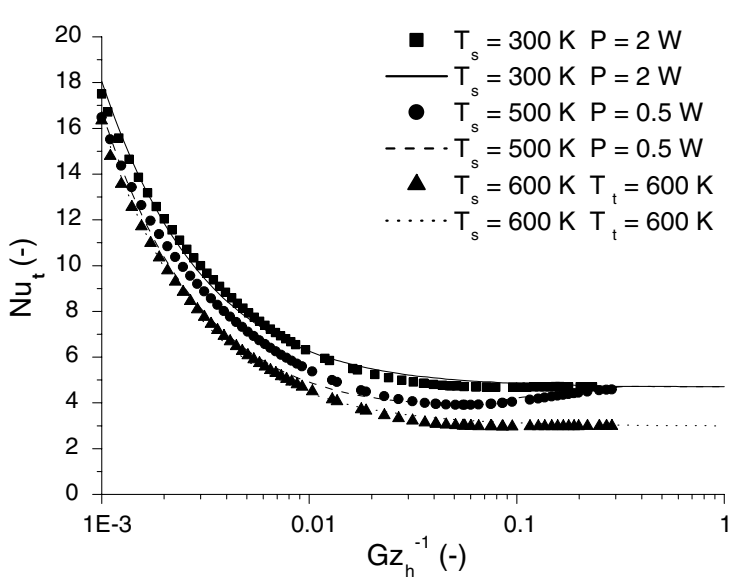

(a) top wall

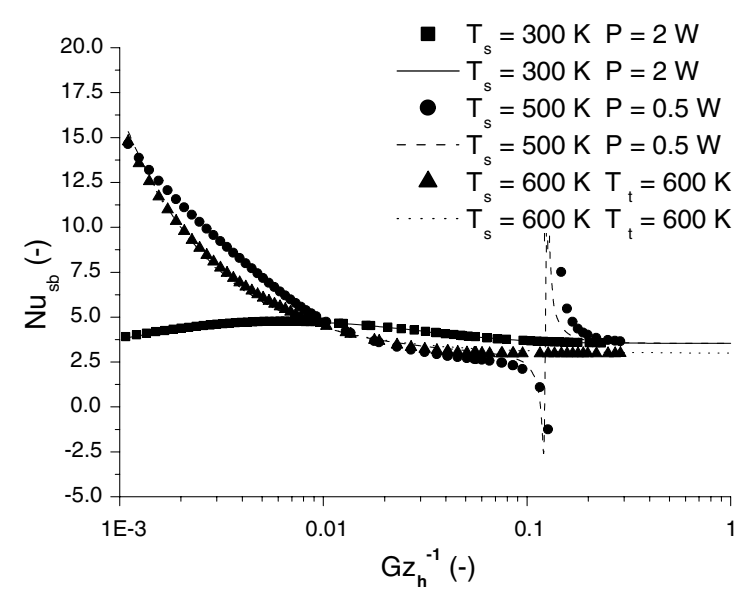

(b) side and bottom wall

Fig. 3. The Nusselt number at the top wall (a) and at the side and bottom wall (b) as a function of the inverse Graetz number for the square microchannel with laminar flow and an inlet gas temperature of $300 \mathrm{~K}$. The data points are obtained from FLUENT simulations. The lines are based on the empirical correlations $6-12 . T_{\mathrm{s}}$ is the side wall temperature, $T_{\mathrm{t}}$ is the top wall temperature, and $P$ is the power input on each of the five heaters.

the temperature dependence of the Nusselt number in the plug flow case is only determined by the temperature ratio:

$R=\frac{T_{\mathrm{s}}-T_{\mathrm{in}}}{\bar{T}_{\mathrm{t}}-T_{\mathrm{s}}}$

The transition of the Nusselt number is similar for laminar and plug flow conditions. At low $G z_{\mathrm{h}}^{-1}$, the Nusselt number approaches the Nusselt number for $R=\infty\left(N u_{R=\infty}\right)$. At high $G z_{\mathrm{h}}^{-1}$, the Nusselt number equals the Nusselt number for the situation when $R=0$ $\left(N u_{R=0}\right)$, see Figs. 3 and 7 . The transition of the Nusselt number is due to the fact that the heat flux through the side and bottom walls will change direction when the gas inside the channel is heated above the temperature of these walls. This is schematically represented in Fig. 4a$\mathrm{d}$. When the mean temperature of the gas $\bar{T}_{\mathrm{g}}$ is lower than the temperature of the side walls $T_{\mathrm{s}}$, the heat flux is pointing inwards (Fig. 4(b)). As soon as the mean gas temperature becomes equal to the temperature of the side and bottom walls, there is only a heat flux from the top side (Fig. 4(c)). When the mean gas temperature rises further, the heat flux through the side and bottom walls will be pointing outwards (Fig. 4(d)). When the heat flux changes direction, $N u_{\mathrm{sb}}$ will go to infinity (Fig. $3(\mathrm{~b})$ ). As soon as the heat flux is reversed (e.g. $G z_{\mathrm{h}}^{-1}=0.13$ for $\left.R=2.93\right), N u_{\mathrm{sb}}$ is negative and reaches to its asymptotic value at large $G z_{\mathrm{h}}^{-1}$.

To describe the transition of the Nusselt number at the top wall in the laminar flow case, we have used the formulas obtained for the plug flow case. From the plug flow calculations (Eqs. (A.14), (A.16)-(A.23)) it can be shown that the Nusselt number for any value of $R$ is described by:

$N u_{i}=N u_{i, R=0} \frac{1+R q_{i}}{1+R q_{i} \frac{N u_{i, R=0}}{N u_{i, R=\infty}}}$

in which $N u_{R=\infty}, N u_{R=0}$, and $q_{i}$ are all functions of $G z_{\mathrm{h}}^{-1}$. The function $q_{i}$ is described empirically from the plug flow correlations because the data from the laminar flow CFD simulations gives quite some scattering of the data at low $G z_{\mathrm{h}}^{-1} . N u_{i, R=0}$ and $N u_{i, R=\infty}$ are determined from the laminar flow CFD simulations. The parameters in the empirical equations were estimated by means of nonlinear regression, using a Marquardt-Levenberg algorithm implemented in ODRPACK [14]. For the top

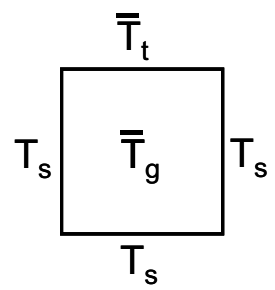

(a)
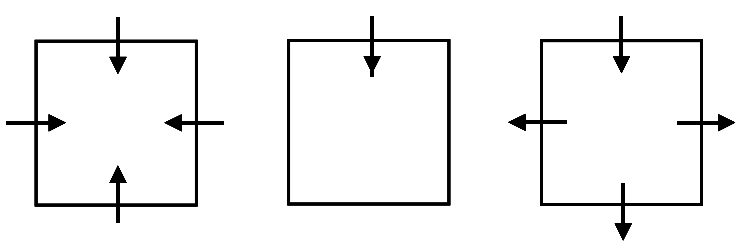

(b) $\overline{T_{\mathrm{g}}}<T_{\mathrm{s}}<\overline{T_{\mathrm{t}}}$

(c) $\overline{T_{\mathrm{g}}}=T_{\mathrm{s}}<\overline{T_{\mathrm{t}}}$

(d) $T_{\mathrm{s}}<\overline{T_{\mathrm{g}}}<\overline{T_{\mathrm{t}}}$

Fig. 4. Schematic representation of the heat flux direction through the channel walls at different temperatures. The arrows represent the direction of the heat flux through the channel walls. 
wall, the empirical equations for $q_{\mathrm{t}}, N u_{\mathrm{t}, R=0}$, and $N u_{\mathrm{t}, R=\infty}$ are very well approximated by (see Fig. 3(a)):

$q_{\mathrm{t}}=1-\tanh \left(5.9 G z_{\mathrm{h}}^{-0.648}\right)$

$N u_{\mathrm{t}, R=0}=4.69\left(1+\frac{G z_{\mathrm{h}}}{233}\right)^{0.809}$

and

$N u_{\mathrm{t}, R=\infty}=2.98\left(1+\frac{G z_{\mathrm{h}}}{181}\right)^{0.906}$

The correlation for the average Nusselt number at the side and bottom walls $N u_{\mathrm{sb}}$ is determined in the same way as Eqs. (7)-(9). The equations for: $q_{\mathrm{sb}}, N u_{\mathrm{sb}, R=0}$, and $N u_{\mathrm{sb}, R=\infty}$ are empirically determined as:

$$
\begin{aligned}
q_{\mathrm{sb}}=\frac{0.0545\left(22.37 G z_{\mathrm{h}}^{-0.848}\right)^{2}}{G z_{\mathrm{h}}^{-1}\left(1-\cosh \left(22.37 G z_{\mathrm{h}}^{-0.848}\right)\right)} \\
N u_{\mathrm{sb}, R=0}=0.40-1.96 \tanh \left(7.3 G z_{\mathrm{h}}^{-0.64}\right) \\
+5.11 \tanh \left(17.9 G z_{\mathrm{h}}^{-0.44}\right) \\
N u_{\mathrm{sb}, R=\infty}=2.98\left(1+\frac{G z_{\mathrm{h}}}{181}\right)^{0.906}
\end{aligned}
$$

With Eqs. (10)-(12), $N u_{\mathrm{sb}}$ can be calculated for any temperature ratio $R$. In Fig. 3(b) it can be seen that Eqs. (10)-(12) well describe the $N u_{\mathrm{sb}}$ as obtained from the FLUENT simulations. The Nusselt numbers $N u_{\mathrm{t}}$ and $N u_{\mathrm{sb}}$ can now be used in Eq. (3) to calculate the mean gas temperature.

For both the laminar flow and plug flow cases, the heat flux reversal (Fig. 4) is observed when the temperature of the side walls is higher then the inlet temperature and lower than the top wall temperature. Because of this heat flux reversal, the Nusselt number at the top wall will approach its asymptotic value further down stream compared to the cases when there is no heat flux reversal. In Table 1 the value of $G z_{\mathrm{h}}^{-1}$ and the corresponding axial position in the microchannel are given at which the Nusselt number has reached $95 \%$ of its asymptotic value. For the laminar flow case, the length for $95 \%$ development of the heat transfer is longer when there is heat flux reversal $(R \neq 0$ and $R \neq \infty)$ compared to the case when there is no heat flux reversal at the side

Table 1

Inverse Graetz number and axial position at which the Nusselt number for a different temperature ratio $R$ has reached $95 \%$ of its asymptotic value

\begin{tabular}{lllllr}
\hline$N u_{\mathrm{t}}(-)$ & \multicolumn{2}{l}{ Laminar flow case } & & \multicolumn{2}{l}{ Plug flow case } \\
\cline { 2 - 3 } \cline { 5 - 6 } & $G z_{\mathrm{h}}^{-1}(-)$ & $z_{95 \%}(\mathrm{~mm})$ & & $G z_{\mathrm{h}}^{-1}(-)$ & $z_{95 \%}(\mathrm{~mm})$ \\
\hline$N u_{R=0}$ & 0.031 & 7 & & 0.048 & 11 \\
$N u_{R=\infty}$ & 0.039 & 9 & & 0.036 & 8 \\
$N u_{R=2.93}$ & 0.2 & 37 & 0.06 & 13 \\
\hline
\end{tabular}

and bottom walls $(R=0$ or $R=\infty)$. When $R=2.93$ $\left(T_{\mathrm{s}}=500 \mathrm{~K}\right.$ and $\left.P=0.5 \mathrm{~W}\right), z_{95 \%}$ is even longer than the reactor length and $N u_{\mathrm{t}}$ will not reach $95 \%$ of its asymptotic value. In microchannel heat sinks for cooling of electrical devices, a long development length is preferred to get a higher overall heat transport coefficient for a better performance [15]. For kinetic research a high heat transport coefficient and an uniform gas temperature along the reaction channel are preferred. When the gas feed temperature is equal to the temperature of the side walls $(R=0)$, the asymptotic value of the $N u_{\mathrm{t}}$ is highest (Fig. 3) and the $z_{95 \%}$ smallest (Table 1).

\subsection{Sherwood correlation for laminar flow}

At the top side of the channel, transport of the reactants to the catalyst takes place while the reaction products are transported from the catalyst to the bulk. The reaction rate of the catalytic partial oxidation of methane is very fast and mass transport limitations are likely to occur [16]. When the reaction rate of a component is mass transport limited, the reaction rate will be equal to the mass flux to the catalytic surface:

$-r=k\left(C-C_{i}\right)$

in which $r$ is the reaction rate; $k$, the mass transport coefficient; $C$, the species concentration in the bulk; and $C_{i}$, the concentration at the catalytic surface. The mass transport coefficient is calculated from the Sherwood number. To calculate the Sherwood number at the catalytic surface, the mass transport is determined from a heat transport simulation. With the CFD package FLUENT, heat transport is simulated with the computational grid as discussed in Section 2.1. As there is no mass transfer at the side and bottom walls, adiabatic boundaries are used. For the catalytic top wall, an isothermal boundary is used as the species concentrations at the catalyst will be constant during stationary operation. From this heat transport calculation, the Nusselt number at the catalytic top wall is calculated using Eq. (1). The Nusselt correlation is then converted using the Chilton-Colburn analogy [17-19] to a mass transport correlation, i.e. by substitution of the Sherwood number $(\mathrm{Sh})$ for the Nusselt number $(\mathrm{Nu})$, and of the Schmidt number $(S c)$ for the Prandtl number $(P r)$. In Fig. 5 the Sherwood number as a function of the inverse Graetz number $\left(G z_{\mathrm{m}}^{-1}\right)$ is shown. The Graetz number is now defined as:

$G z_{\mathrm{m}}=\operatorname{ReSc} \frac{d}{z}$

For the mass transport simulations, it is found that $S h=2.43$ at $G z_{\mathrm{m}}^{-1}>0.1$, which is in agreement with the literature [20]. $S h$ as function of $G z_{\mathrm{m}}^{-1}$ is very well approximated by (see Fig. 5): 


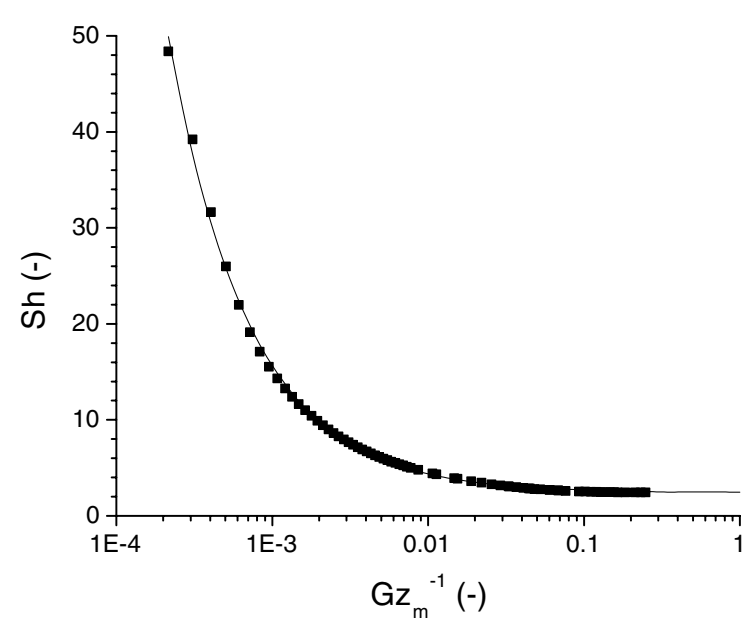

Fig. 5. The Sherwood number as a function of the inverse Graetz number for a square microchannel with laminar flow and mass transport only taking place to the top wall of the channel. The data points are obtained from a FLUENT simulation. The line is based on the empirical correlation: Eq. (15).

$S h=2.43\left(1+\left(\frac{G z_{\mathrm{m}}}{132}\right)^{0.835}\right)$

At $G z_{\mathrm{m}}^{-1}=0.08$, the Sherwood number reaches its asymptotic value for $95 \%$. Considering a residence time of 1 $\mathrm{ms}$, the inverse Graetz number of 0.08 corresponds to a length of $18 \mathrm{~mm}$ at which the mass transport is $95 \%$ developed. For the microreactor used a length of $18 \mathrm{~mm}$ corresponds to $60 \%$ of the total length. Therefore it is necessary to calculate the Sherwood number as a function of the axial position inside the reactor instead of using a constant value as is done with conventional reactors. With Eq. (15) the Sherwood number and therefore the mass transport coefficient can be calculated along the length of the reactor. The mass transport coefficient can be used in Eq. (13) to calculate the reaction rate.

\section{Experimental validation}

The FLUENT simulations (Section 2.2) are validated by comparing the calculated temperature at the microchannel top wall with the measured temperature at the top wall.

\subsection{Microreactor fabrication and connections}

The microreactor used for the experiments (see Fig. 1) is built at $\mathrm{MESA}^{+}$Research Institute and is made from silicon wafers using standard silicon-based micromachining technology. To fabricate this reactor, a silicon wafer, polished on both sides, is doped on one side with boron. Afterwards an annealing step is carried out at $1400 \mathrm{~K}$. The annealing step determines the diffusion depth of the boron: the longer the annealing time, the thicker the boron-doped silicon layer and hence the thicker the final top layer covering the reaction channel. After doping and annealing a thin low stress silicon nitride layer is deposited. This layer will insulate the platinum filaments from the silicon substrate. The platinum metal structures (viz. heaters and temperature sensors) are applied using lithography with an image reversal resist, sputtering of the Pt film and lift off in acetone. The flow channel is formed using lithography and three etching steps. First $470 \mu \mathrm{m}$ deep channels are etched by deep reactive ion etching (DRIE), followed by wet chemical etching in $\mathrm{KOH}$, and $\mathrm{KOH} / \mathrm{IPA}$ as etchants. These three etch steps result in a thin top wall of the channel with a high uniformity. A second silicon wafer is used for the bottom wall of the reactor. In this wafer the holes for the gas inlet and outlet of the channel are formed by means of powder blasting. After cleaning both wafers, the reactor is assembled by fusion bonding. The microreactor is mounted to an alumina block with the gas inlet and gas outlet connections. The electrical connections of the heaters and temperature sensors are contacted to a printed circuit board by springs. The current and voltage readings of the heaters and temperature sensors are collected in a data-acquisition system.

\subsection{Experiments}

The FLUENT simulations are validated by measurements, by using the same input parameters for the simulation as the experimental conditions (the power supplied by the heaters, the gas properties, and the gas

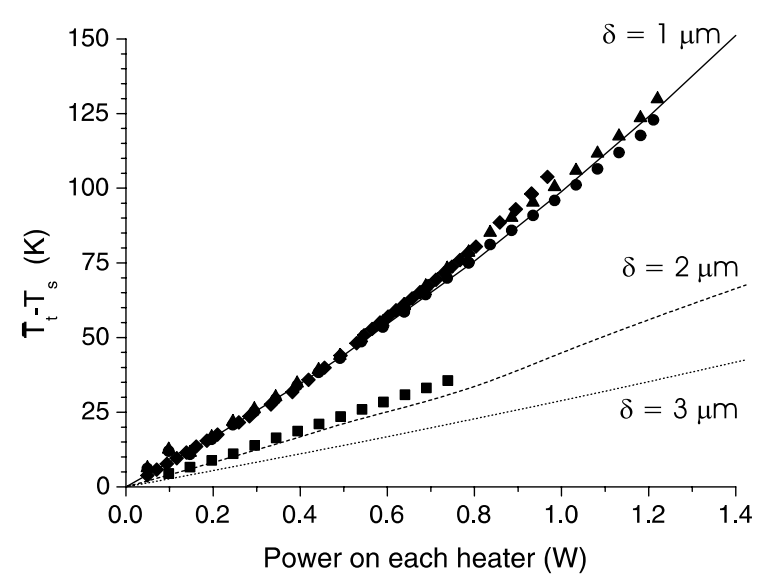

Fig. 6. The difference between the top wall temperature and the side wall temperature as a function of the power supplied by each of the five heaters. The data points are experimental data obtained from measurements with four different microreactors, one reactor with top wall thickness $\delta=1.9 \mu \mathrm{m}$ and three reactors with $\delta=1.0 \mu \mathrm{m}$ the lines are obtained from FLUENT simulations for different $\delta$. 
Table 2

Nusselt and Sherwood correlations for a square channel heated from the top side ( $R$ is the temperature ratio defined by Eq. (5))

\begin{tabular}{|c|c|c|}
\hline$R$ & Laminar flow & Plug flow \\
\hline 0 & $N u_{\mathrm{t}}=4.69\left(1+\frac{G z_{\mathrm{h}}}{233}\right)^{0.809}$ & $N u_{\mathrm{t}}=4.597\left(1+\left(\frac{G z}{63.7}\right)^{3 / 2}\right)^{1 / 3}$ \\
\hline$\infty$ & $N u_{\mathrm{t}}=2.98\left(1+\frac{G z_{\mathrm{h}}}{181}\right)^{0.906}$ & $N u_{\mathrm{t}}=4.935\left(1+\left(\frac{G z}{71.3}\right)^{3 / 2}\right)^{1 / 3}$ \\
\hline \multirow[t]{2}{*}{ All } & $N u_{\mathrm{t}}=N u_{\mathrm{t}, R=0} \frac{1+R q_{\mathrm{t}}}{1+R q_{\mathrm{t}} \frac{N u_{\mathrm{t}, R=0}}{N u_{\mathrm{t}, R=\infty}}}$ & $N u_{\mathrm{t}}=N u_{\mathrm{t}, R=0} \frac{1+R q_{\mathrm{t}}}{1+R q_{\mathrm{t}} \frac{N u_{\mathrm{t}, R=0}}{N u_{\mathrm{t}, R=\infty}}}$ \\
\hline & $q_{\mathrm{t}}=1-\tanh \left(5.9 G z_{\mathrm{h}}^{-0.648}\right)$ & $q_{\mathrm{t}}=1-\tanh \left(5.9 G z_{\mathrm{h}}^{-0.648}\right)$ \\
\hline 0 & $\begin{aligned} N u_{\mathrm{sb}}= & 0.40-1.96 \tanh \left(7.3 G z_{\mathrm{h}}^{-0.64}\right) \\
& +5.11 \tanh \left(17.9 G z_{\mathrm{h}}^{-0.44}\right)\end{aligned}$ & $\begin{aligned} N u_{\mathrm{sb}}= & 3.987-\frac{2}{3} \tanh \left(6.2 G z_{\mathrm{h}}^{-0.52}\right) \\
& +0.445 \tanh \left(15.6 G z_{\mathrm{h}}^{-1.27}\right)\end{aligned}$ \\
\hline$\infty$ & $N u_{\mathrm{sb}}=2.98\left(1+\frac{G z_{\mathrm{h}}}{181}\right)^{0.906}$ & $N u_{\mathrm{sb}}=4.935\left(1+\left(\frac{G z_{\mathrm{h}}}{71.3}\right)^{3 / 2}\right)^{1 / 3}$ \\
\hline \multirow[t]{3}{*}{ All } & $N u_{\mathrm{sb}}=N u_{\mathrm{sb}, R=0} \frac{1+R q_{\mathrm{sb}}}{1+R q_{\mathrm{sb}} \frac{N u_{\mathrm{sb}, R=0}}{N u_{\mathrm{sb}, R=\infty}}}$ & $N u_{\mathrm{sb}}=N u_{\mathrm{sb}, R=0} \frac{1+R q_{\mathrm{sb}}}{1+R q_{\mathrm{sb}} \frac{N u_{\mathrm{sb}, R=0}}{N u_{\mathrm{sb}, R=\infty}}}$ \\
\hline & $q_{\mathrm{sb}}=\frac{0.0545\left(22.37 G z_{\mathrm{h}}^{-0.848}\right)^{2}}{G z_{\mathrm{h}}^{-1}\left(1-\cosh \left(22.37 G z_{\mathrm{h}}^{-0.848}\right)\right)}$ & $q_{\mathrm{sb}}=\frac{0.0545\left(22.37 G z_{\mathrm{h}}^{-0.848}\right)^{2}}{G z_{\mathrm{h}}^{-1}\left(1-\cosh \left(22.37 G z_{\mathrm{h}}^{-0.848}\right)\right)}$ \\
\hline & $S h_{\mathrm{t}}=2.43\left(1+\left(\frac{G z_{\mathrm{m}}}{132}\right)^{0.835}\right)$ & $S h_{\mathrm{t}}=2.467\left(1+\frac{G z_{\mathrm{m}}}{27.3}\right)^{0.407}$ \\
\hline
\end{tabular}

velocity at the inlet). The temperature sensors on top of the microchannel are calibrated by measuring their resistance while the reactor is heated inside an oven. In Fig. 6 the simulated and measured temperature difference between the top wall and the side wall are plotted against the power supplied by the heaters. For the measurements four different microreactors are used. The sensor readings and simulated data are both taken 3.8 mm downstream of the beginning of the heated top wall. To measure the thickness of the channel top wall $\delta$, the reactors are broken and $\delta$ is determent by means of a scanning electron microscope. One reactor with a top wall thickness of $\delta=1.9 \mu \mathrm{m}$ and three reactors with $\delta=1.0 \mu \mathrm{m}$ were used for the experiments. From Fig. 6 it can be seen that the simulated data correspond very well with the experimental data and the used model is valid. The model can therefore be used to determine the thickness of the channel top layer without breaking the reactor.

\section{Concluding remarks}

In the present study CFD simulations are used to determine the heat and mass transfer characteristics under laminar flow conditions in a square microchannel. The CFD simulations are validated with experiments. From these simulations empirical Nusselt and Sherwood correlations are derived. To describe the heat and mass transport for laminar flow conditions, Nusselt and Sherwood correlations for plug flow conditions are used which are derived from the analytical solution. In Table 2 the obtained correlations for laminar flow and plug flow are summarized. These correlations are based on dimensionless numbers (Nusselt, Sherwood, and Graetz number) and can therefore also be used when the dimensions of the square channel change. For both laminar flow and plug flow conditions, a heat flux reversal is observed on the side and bottom walls of the channel, when the temperature of the side and bottom walls is higher then the gas inlet temperature. This heat flux reversal is described by the obtained Nusselt correlations. When the inlet gas temperature is equal to the temperature of the side and bottom walls, the asymptotic value of the Nusselt number is the highest. A high Nusselt number results in a high heat transfer coefficient which is preferred for kinetic research. The empirical Nusselt and Sherwood correlations will be used further to model heat and mass transport inside the microreactor to determine reaction kinetic information. 


\section{Acknowledgements}

The financial support by the Dutch Technology Foundation (STW), Shell Global Solutions International B.V., and Netherlands Energy Research Foundation ECN, project no. EFC.5134 is gratefully acknowledged.

\section{Appendix A. Heat and mass transport for plug flow}

\section{A.1. Nusselt correlation for plug flow}

Heat transport inside a square channel is examined analytically for steady state plug flow conditions with constant gas properties. Although at the top wall of the reactor heat is produced by an exothermic reaction or by the heaters, it is considered as a thermal boundary condition. Due to the high heat conductivity of the silicon the temperature of the top wall is a function of the width of the channel and almost not of the channel length, this is confirmed by the FLUENT calculation. The other tree walls are assumed to be isothermal. Heat transfer takes place at all four channel walls and as the temperature of the four walls is not the same they are examined separately. The coordinate system used is shown in Fig. 2. The average Nusselt number at the top wall is defined as [17]:

$N u_{\mathrm{t}}(z)=\frac{\left.\int_{0}^{d} \frac{\partial T_{\mathrm{g}}(x, y, z)}{\partial y}\right|_{y=d} \mathrm{~d} x}{\bar{T}_{\mathrm{t}}(z)-\bar{T}_{\mathrm{g}}(z)}$

In Eq. (A.1) $T_{\mathrm{g}}$ is the gas temperature, $\bar{T}_{\mathrm{t}}$ is a width weighted average temperature of the top wall at location $z$, and $\bar{T}_{\mathrm{g}}$ is the average gas temperature at location $z$, which is calculated as the bulk mean fluid temperature over a channel cross-section:

$\bar{T}_{\mathrm{g}}(z)=\frac{\int_{0}^{d} \int_{0}^{d} T_{\mathrm{g}}(x, y, z) \rho v_{z} c_{p} \mathrm{~d} x \mathrm{~d} y}{\int_{0}^{d} \int_{0}^{d} \rho v_{z} c_{p} \mathrm{~d} x \mathrm{~d} y}$

To calculate the gas temperature $T_{\mathrm{g}}$ inside the square channel from Eqs. (A.1) and (A.2) we have to simultaneously solve the momentum, continuity and energy equations with the boundary conditions. Under the assumption of plug flow (constant gas properties in crosssection perpendicular to $z$-axis) and neglecting axial thermal conduction, natural convection, viscous dissipation, and internal energy sources, the previous system of equations reduces to the steady state energy equation:

$\kappa\left(\frac{\partial^{2} T_{\mathrm{g}}(x, y, z)}{\partial x^{2}}+\frac{\partial^{2} T_{\mathrm{g}}(x, y, z)}{\partial y^{2}}\right)=\rho c_{p} v_{z} \frac{\partial T_{\mathrm{g}}(x, y, z)}{\partial z}$
To solve this equation, we introduce dimensionless coordinates $\hat{x}$ and $\hat{y}$, while $T_{\mathrm{g}}(x, y, z)$ is replaced by a function $f(x, y, z)$ (Eq. (A.4)) in which $T_{\infty}$ is the temperature at an infinite distance downstream of the entrance $\left(z=\infty, \frac{\partial T_{\mathrm{g}}}{\partial z}=0\right)$ :

$\hat{x}=\frac{x}{d}, \quad \hat{y}=\frac{y}{d}, \quad f=\frac{T_{\infty}(x, y)-T_{\mathrm{g}}(x, y, z)}{\bar{T}_{\mathrm{t}}-T_{\mathrm{s}}}$

which gives

$\frac{\partial^{2} f(x, y, z)}{\partial \hat{x}^{2}}+\frac{\partial^{2} f(x, y, z)}{\partial \hat{y}^{2}}=\frac{\partial f(x, y, z)}{\partial G z_{\mathrm{h}}^{-1}}$

Eq. (A.5) is solved with the following boundary conditions: $f=0$ at $\hat{x}=0, f=0$ at $\hat{x}=1, f=0$ at $\hat{y}=0$, $f=0$ at $\hat{y}=1$, and $f=T_{\infty}-T_{\text {in }}$ at $G z_{\mathrm{h}}^{-1}=0$ (reactor inlet), with $T_{\text {in }}$ the gas temperature at the inlet. $T_{\infty}$ is calculated by solving the heat balance equation on a channel cross-section at $z=\infty$ :

$\frac{\partial^{2} g(x, y)}{\partial \hat{x}^{2}}+\frac{\partial^{2} g(x, y)}{\partial \hat{y}^{2}}=0 \quad$ with $g(x, y)=\frac{T_{\infty}(x, y)-T_{\mathrm{s}}}{\bar{T}_{\mathrm{t}}-T_{\mathrm{s}}}$

The boundary conditions for Eq. (A.6) are: $g=0$ at $\hat{x}=0, g=0$ at $\hat{x}=1, g=0$ at $\hat{y}=0$, and $g=\left(T_{\infty}-T_{\mathrm{s}}\right) /$ $\left(\bar{T}_{\mathrm{t}}-T_{\mathrm{s}}\right)$ at $\hat{y}=1$.

To solve Eq. (A.6) for the boundary conditions, $T_{\infty}$ at $\hat{y}=1$ equals $T_{\mathrm{t}} . T_{\mathrm{t}}$ is calculated by solving the heat balance of the thin top sheet:

$L \delta \kappa \frac{\partial^{2} T_{\mathrm{t}}}{\partial \hat{x}^{2}}+P d-h_{\mathrm{o}} d^{2} L\left(T_{\mathrm{t}}-T_{\mathrm{o}}\right)-h_{\mathrm{i}} d^{2} L\left(T_{\mathrm{t}}-T_{\mathrm{i}}\right)=0$

in which $h_{\mathrm{o}}$ and $h_{\mathrm{i}}$ are the heat transfer coefficients outside and inside the reactor respectively; and $T_{\mathrm{o}}$ and $T_{\mathrm{i}}$, the gas temperatures outside and inside the reactor respectively $\left(T_{\mathrm{i}}=\bar{T}_{\mathrm{g}}\right)$. Rewriting Eq. (A.7) gives:

$\frac{\partial^{2} T_{\mathrm{t}}}{\partial \hat{x}^{2}}-\alpha T_{\mathrm{t}}+\beta=0$

with

$\alpha=\frac{\left(h_{\mathrm{o}}+h_{\mathrm{i}}\right) d^{2}}{\delta \kappa}, \quad$ and $\quad \beta=\frac{P d^{2}}{V_{\mathrm{t}} \kappa}+\frac{h_{\mathrm{o}} d^{2} T_{\mathrm{o}}}{\delta \kappa}+\frac{h_{\mathrm{i}} d^{2} T_{\mathrm{i}}}{\delta \kappa}$

Eq. (A.8) is solved with the boundary conditions $T=T_{\mathrm{s}}$ at $\hat{x}=0$ and $T=T_{\mathrm{s}}$ at $\hat{x}=1$ to give the equation for the top wall temperature:

$T_{\mathrm{t}}=\frac{\beta}{\alpha}+\left(T_{\mathrm{s}}-\frac{\beta}{\alpha}\right) \frac{\cosh \left(\sqrt{\alpha}\left(\hat{x}-\frac{1}{2}\right)\right)}{\cosh \frac{\sqrt{\alpha}}{2}}$

Eq. (A.10) is well approximated by:

$T_{\mathrm{t}}=6\left(\bar{T}_{\mathrm{t}}-T_{\mathrm{s}}\right)\left(\hat{x}-\hat{x}^{2}\right)+T_{\mathrm{s}}$ 
With Eq. (A.11) the boundary conditions for Eq. (A.6) become: $g=0$ at $\hat{x}=0, g=0$ at $\hat{x}=1, g=0$ at $\hat{y}=0$, and $g=6\left(\hat{x}-\hat{x}^{2}\right)$ at $\hat{y}=1$, it follows that:

$$
\begin{aligned}
T_{\infty}(x, y)= & T_{\mathrm{s}}+24\left(\bar{T}_{\mathrm{t}}-T_{\mathrm{s}}\right) \sum_{m=1}^{\infty} \frac{1-\cos (m \pi)}{m^{3} \pi^{3} \sinh (m \pi)} \\
& \times \sin (m \pi \hat{x}) \sinh (m \pi \hat{y})
\end{aligned}
$$

By solving Eq. (A.5) for the function $f$, the temperature profile inside the channel $T_{\mathrm{g}}(x, y, z)$ can be calculated:

$$
\begin{aligned}
T_{\mathrm{g}}(x, y, z)= & T_{\infty}(x, y)-\left(\bar{T}_{\mathrm{t}}-T_{\mathrm{s}}\right) \sum_{k=1}^{\infty} \sum_{m=1}^{\infty} \beta_{k, \mathrm{~m}} \\
& \times \sin (k \pi \hat{x}) \sin (m \pi \hat{y}) \mathrm{e}^{-\left(k^{2}+m^{2}\right) \pi^{2} G_{\mathrm{h}}^{-1}}
\end{aligned}
$$

with

$$
\begin{aligned}
\beta_{k, \mathrm{~m}}=4 & \left(\frac{T_{\mathrm{s}}-T_{\mathrm{in}}}{\bar{T}_{\mathrm{t}}-T_{\mathrm{s}}}(1-\cos (m \pi))\right. \\
& \left.+\frac{12}{k^{2} \pi^{2}} \frac{m^{2}(-1)^{m+1}}{k^{2}+m^{2}}\right) \frac{1-\cos (k \pi)}{k m \pi^{2}}
\end{aligned}
$$

Substitution of Eq. (A.13) in Eq. (A.2) gives $\bar{T}_{\mathrm{g}}$. For plug flow calculations $\rho, v_{z}$, and $c_{p}$ are constant in a cross-section perpendicular to the $z$-axis. They are only a function of $\bar{T}_{\mathrm{g}}(z)$ and therefore they cancel out of Eq. (A.2) giving:

$$
\bar{T}_{\mathrm{g}}(z)=\int_{0}^{1} \int_{0}^{1} T_{\mathrm{g}}(z) \mathrm{d} \hat{x} \mathrm{~d} \hat{y}
$$

leading to

$$
\begin{aligned}
\bar{T}_{\mathrm{g}}(z)= & T_{\mathrm{s}}+24\left(\bar{T}_{\mathrm{t}}-T_{\mathrm{s}}\right) \sum_{m=1}^{\infty} \frac{(1-\cos (m \pi))^{2}}{m^{5} \pi^{5}} \\
& \times\left(\frac{1}{\tanh (m \pi)}-\frac{1}{\sinh (m \pi)}\right) \\
& -\left(\bar{T}_{\mathrm{t}}-T_{\mathrm{s}}\right) \sum_{m=1}^{\infty} \sum_{k=1}^{\infty} \beta_{k, \mathrm{~m}} \\
& \times \frac{1-\cos (k \pi)}{k \pi} \frac{1-\cos (m \pi)}{m \pi} \mathrm{e}^{-\left(k^{2}+m^{2}\right) \pi^{2} G z_{\mathrm{h}}^{-1}}
\end{aligned}
$$

The Nusselt number at the top wall can now be calculated by substitution of Eqs. (A.13) and (A.15) into Eq. (A.1), giving:

$N u_{\mathrm{t}}=\frac{A_{\mathrm{t}}+\sum_{m=1}^{\infty} \sum_{k=1}^{\infty} \beta_{k, \mathrm{~m}} \frac{m}{k} \cos (m \pi)(1-\cos (k \pi)) \mathrm{e}^{-\left(k^{2}+m^{2}\right) \pi^{2} G z_{\mathrm{h}}^{-1}}}{B_{\mathrm{t}}+\sum_{m=1}^{\infty} \sum_{k=1}^{\infty} \beta_{k, \mathrm{~m}} \frac{1-\cos (k \pi)}{k \pi} \frac{1-\cos (m \pi)}{m \pi} \mathrm{e}^{-\left(k^{2}+m^{2}\right) \pi^{2} G z_{\mathrm{h}}^{-1}}}$

where the constants $A_{\mathrm{t}}$ and $B_{\mathrm{t}}$ follow from:

$A_{\mathrm{t}}=24 \sum_{n=1}^{\infty} \frac{(1-\cos (n \pi))^{2}}{n^{3} \pi^{3} \sinh (n \pi)} \cosh (n \pi)$ and

$B_{\mathrm{t}}=1-24 \sum_{n=1}^{\infty} \frac{(1-\cos (n \pi))^{2}}{n^{5} \pi^{5} \sinh (n \pi)}(\cosh (n \pi)-1)$

It follows that $A_{\mathrm{t}}=3.26809$ and $B_{\mathrm{t}}=0.71087$.

The Nusselt number at the side walls is given by:

$$
\begin{aligned}
& N u_{\mathrm{s}}=-\frac{\left.\int_{0}^{1} \frac{\partial T_{\mathrm{g}}}{\partial \hat{x}}\right|_{\hat{x}=0} \mathrm{~d} \hat{y}}{\bar{T}_{\mathrm{s}}-\bar{T}_{\mathrm{g}}} \\
& N u_{\mathrm{s}}=\frac{-A_{\mathrm{s}}+\sum_{m=1}^{\infty} \sum_{k=1}^{\infty} \beta_{k, \mathrm{~m}} \frac{k}{m}(1-\cos (m \pi)) \mathrm{e}^{-\left(k^{2}+m^{2}\right) \pi^{2} G z_{\mathrm{h}}^{-1}}}{B_{\mathrm{s}}+\sum_{m=1}^{\infty} \sum_{k=1}^{\infty} \beta_{k, \mathrm{~m}} \frac{1-\cos (k \pi)}{k \pi} \frac{1-\cos (m \pi)}{m \pi} \mathrm{e}^{-\left(k^{2}+m^{2}\right) \pi^{2} G z_{\mathrm{h}}^{-1}}}
\end{aligned}
$$

with the following constants:

$A_{\mathrm{s}}=24 \sum_{n=1}^{\infty} \frac{(1-\cos (n \pi))^{2}}{n^{3} \pi^{3} \sinh (n \pi)}(\cosh (n \pi)-1)$

and

$B_{\mathrm{s}}=-24 \sum_{n=1}^{\infty} \frac{(1-\cos (n \pi))^{2}}{n^{5} \pi^{5} \sinh (n \pi)}(\cosh (n \pi)-1)$

After carrying out the summations, it follows that $A_{\mathrm{s}}=1.49999$ and $B_{\mathrm{s}}=-0.28913$. from:

The Nusselt number at the bottom wall is derived

$$
\begin{aligned}
& N u_{\mathrm{b}}=-\frac{\left.\int_{0}^{1} \frac{\partial T_{\mathrm{g}}}{\partial \hat{y}}\right|_{\hat{y}=0} \mathrm{~d} \hat{x}}{\overline{T_{\mathrm{b}}}-\bar{T}_{\mathrm{g}}} \\
& N u_{\mathrm{b}}=\frac{A_{\mathrm{b}}+\sum_{m=1}^{\infty} \sum_{k=1}^{\infty} \beta_{k, \mathrm{~m}} \frac{m}{k}(1-\cos (k \pi)) \mathrm{e}^{-\left(k^{2}+m^{2}\right) \pi^{2} G z_{\mathrm{h}}^{-1}}}{B_{\mathrm{b}}+\sum_{m=1}^{\infty} \sum_{k=1}^{\infty} \beta_{k, \mathrm{~m}} \frac{1-\cos (k \pi)}{k \pi} \frac{1-\cos (m \pi)}{m \pi} \mathrm{e}^{-\left(k^{2}+m^{2}\right) \pi^{2} G z_{\mathrm{h}}^{-1}}}
\end{aligned}
$$

with the constants $A_{\mathrm{b}}$ and $B_{\mathrm{b}}$ :

$A_{\mathrm{b}}=24 \sum_{n=1}^{\infty} \frac{(1-\cos (n \pi))^{2}}{n^{3} \pi^{3} \sinh (n \pi)}$

and $B_{\mathrm{b}}=B_{\mathrm{s}}=-0.28913$. It is found that $A_{\mathrm{b}}=0.26811$.

The temperature dependence of the Nusselt number for plug flow is determined by the temperature ratio in Eq. (A.14):

$R=\frac{T_{\mathrm{s}}-T_{\text {in }}}{\bar{T}_{\mathrm{t}}-T_{\mathrm{s}}}$

By making use of this temperature ratio and the Nusselt numbers at $R=0$ and $R=\infty$, it can be shown that the Nusselt numbers for any $R$ can be described by:

$N u_{i}=N u_{i, R=0} \frac{1+R q_{i}}{1+R q_{i} \frac{N u_{i, R=0}}{N u_{i, R=\infty}}}$

in which $q_{i}, N u_{i, R=0}$, and $N u_{i, R=\infty}$ are functions of $G z_{\mathrm{h}}^{-1}$ which are described empirically for the top wall as: 
$q_{\mathrm{t}}=1-\tanh \left(5.9 G z_{\mathrm{h}}^{-0.647}\right)$

$N u_{\mathrm{t}, R=0}=4.597\left(1+\left(\frac{G z_{\mathrm{h}}}{63.7}\right)^{3 / 2}\right)^{1 / 3}$

and

$N u_{\mathrm{t}, R=\infty}=4.935\left(1+\left(\frac{G z_{\mathrm{h}}}{71.3}\right)^{3 / 2}\right)^{1 / 3}$

The Nusselt numbers for the bottom and side walls are not needed separately (Eq. (2)), therefore area weighted average of the two is used $\left(N u_{\mathrm{sb}}=\frac{2 N u_{\mathrm{s}}+N u_{\mathrm{b}}}{3}\right)$. At $R=\infty$, $N u_{\mathrm{t}}=N u_{\mathrm{s}}=N u_{\mathrm{b}}$. The empirical correlation $q_{\mathrm{sb}}$ and $N u_{\mathrm{sb}, R=0}$ are determined as:

$$
\begin{array}{r}
q_{\mathrm{sb}}=\frac{0.0545\left(22.37 G z_{\mathrm{h}}^{-0.848}\right)^{2}}{G z_{\mathrm{h}}^{-1}\left(1-\cosh \left(22.37 G z_{\mathrm{h}}^{-0.848}\right)\right)} \\
N u_{\mathrm{sb}, R=0}=3.987-\frac{2}{3} \tanh \left(6.2 G z_{\mathrm{h}}^{-0.52}\right) \\
+0.445 \tanh \left(15.6 G z_{\mathrm{h}}^{-1.27}\right)
\end{array}
$$

In Fig. 7(a) and (b) the Nusselt numbers for the top wall $N u_{\mathrm{t}}$, and the average Nusselt number at the side and bottom walls $N u_{\mathrm{sb}}$ are plotted against the inverse Graetz number $\left(G z_{\mathrm{h}}^{-1}\right)$. The dots are calculated by the analytical solution, the lines are the empirical equations. From these figures it can be seen that the analytical and empirical correlations correspond very well.

\section{A.2. Sherwood correlation for plug flow}

Although we do not need a mass transport correlations for plug flow, we solved it analytically for completeness. Mass transport only takes place at the catalytic top side of the channel. As there is no mass transport taking place through the side walls of the channel, the mass balance does not need to be solved in the $x$-direction (see Fig. 2 for coordinate system used). The mass transport is determined from a heat transport calculation. By making use of the Chilton-Colburn analogy the obtained heat transport correlation is then converted to a mass transport correlation. For the catalytic wall an isothermal boundary is used as the species concentrations will be constant for stationary operation. No mass transport takes place through the bottom wall of the channel. On this wall an adiabatic boundary conditions is used. The Nusselt number at the top wall is calculated by:

$N u_{\mathrm{t}}=\frac{\left.\int_{0}^{1} \frac{\partial T_{\mathrm{g}}}{\partial \hat{y}}\right|_{\hat{y}=1} \mathrm{~d} \hat{x}}{T_{\mathrm{t}}-\bar{T}_{\mathrm{g}}}$

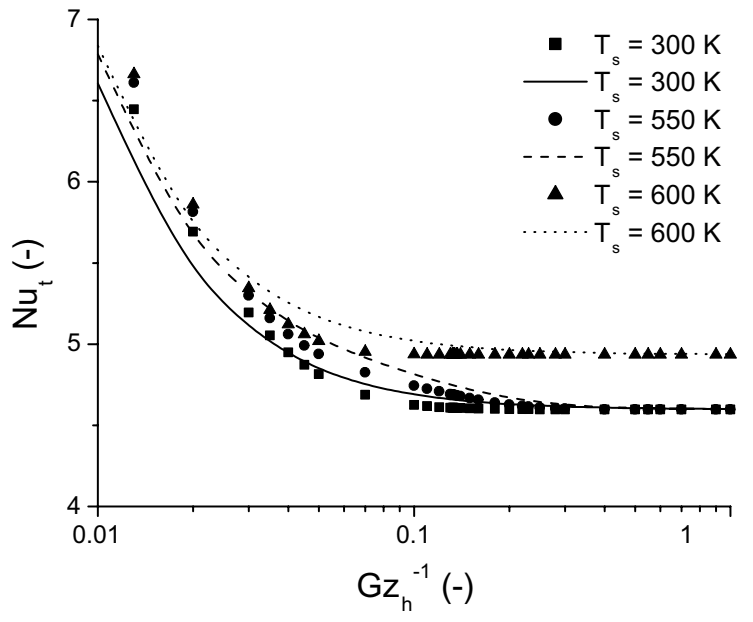

(a) top wall

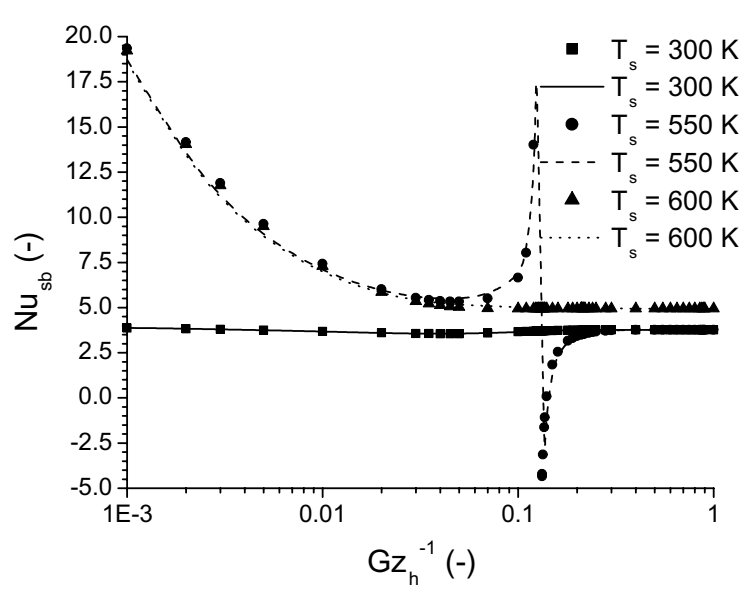

(b) side and bottom wall

Fig. 7. The Nusselt number at the top wall (a) and at the side and bottom wall (b) as a function of the inverse Graetz number for the square channel with plug flow. For the calculations, an inlet temperature $300 \mathrm{~K}$ and an average top wall temperature of $600 \mathrm{~K}$ is used. The data points are obtained from Eqs. (A.14) and (A.16)-(A.23). The lines are based on the empirical correlations (A.25)-(A.30).

To calculate the gas temperature, the two-dimensional heat balance over the channel is solved:

$\frac{\partial^{2} T_{\mathrm{g}}}{\partial \hat{y}^{2}}=\frac{\partial T_{\mathrm{g}}}{\partial G z_{\mathrm{h}}^{-1}}$

The heat balance is solved by replacing the gas temperature $T_{\mathrm{g}}$ by a dimensionless function $j$ :

$j=\frac{T_{\mathrm{t}}-T_{\mathrm{g}}}{T_{\mathrm{t}}-T_{\mathrm{in}}}$

which gives 
$\frac{\partial^{2} j}{\partial \hat{y}^{2}}=\frac{\partial j}{\partial G z_{\mathrm{h}}^{-1}}$

Eq. (A.34) is solved for the function $j$ with the following boundary conditions: $\frac{\partial j}{\partial y}=0$ at $\hat{y}=0, j=0$ at $\hat{y}=1$, and $j=1$ at $G z_{\mathrm{h}}^{-1}=0$, to calculate $T_{\mathrm{g}}$ :

$$
\begin{aligned}
T_{\mathrm{g}}= & T_{\mathrm{t}}-\left(T_{\mathrm{t}}-T_{\mathrm{in}}\right) \frac{4}{\pi} \sum_{n=1}^{\infty} \frac{(-1)^{n+1}}{2 n-1} \cos \left(\frac{2 n-1}{2} \hat{y}\right) \\
& \times \mathrm{e}^{-\left(\frac{2 n-1}{2} \pi\right)^{2} G z_{\mathrm{h}}^{-1}}
\end{aligned}
$$

The mean gas temperature $\bar{T}_{\mathrm{g}}$ at a channel cross-section is obtained from:

$\bar{T}_{\mathrm{g}}=\int_{0}^{1} T_{\mathrm{g}} \mathrm{d} \hat{y}$

leading to

$\bar{T}_{\mathrm{g}}=T_{\mathrm{t}}+\left(T_{\mathrm{t}}-T_{\text {in }}\right) \frac{8}{\pi} \sum_{n=1}^{\infty} \frac{1}{(2 n-1)^{2}} \mathrm{e}^{-\left(\frac{2 n-1}{2} \pi\right)^{2} G z_{\mathrm{h}}^{-1}}$

The Nusselt number at the top wall is calculated by substitution of Eqs. (A.35), (A.36) into (A.31). By using the Chilton-Colburn analogy the Sherwood number is obtained:

$S h=\frac{\pi^{2}}{4} \frac{\sum_{n=1}^{\infty} \mathrm{e}^{-\left(\frac{2 n-1}{2} \pi\right)^{2} G z_{\mathrm{m}}^{-1}}}{\sum_{n=1}^{\infty} \frac{1}{2 n-1} \mathrm{e}^{-\left(\frac{2 n-1}{2} \pi\right)^{2} G z_{\mathrm{m}}^{-1}}}$

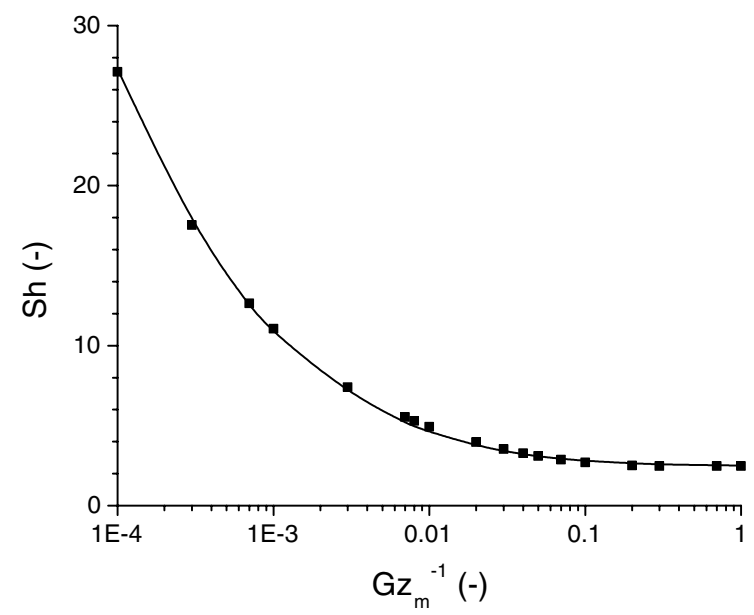

Fig. 8. The Sherwood number as a function of the inverse Graetz number for a square channel with plug flow and mass transport only taking place to the top wall of the channel. The data points are obtained from Eq. (A.37). The line is based on the empirical correlation: Eq. (A.38).
Eq. (A.37) is approximated by the empirical correlation:

$S h=2.467\left(1+\frac{G z_{\mathrm{m}}}{27.3}\right)^{0.407}$

When $G z_{\mathrm{m}}^{-1}<0.001$ Sherwood is proportional to $G z_{\mathrm{m}}^{0.5}$. In Fig. 8, Eqs. (A.37) and (A.38) are plotted.

\section{References}

[1] K.F. Jensen, Microreaction engineering is small better? Chem. Eng. Sci. 56 (2001) 293-303.

[2] R. Srinivasan, I. Hsing, P.E. Berger, K.F. Jensen, S.L. Firebaugh, M.A. Schmidt, M.P. Harold, J.J. Lerou, F. Ryley, Micromachined reactors for catalytic partial oxidation reactions, AIChE J. 43 (11) (1997) 3059-3069.

[3] W. Ehrfeld, V. Hessel, H. Löwe, Microreactors New technology for Modern Chemistry, Wiley-VCH, Weinheim, 2000.

[4] D.J. Quiram, I. Hsing, A.J. Franz, K.F. Jensen, Design issues for membrane-based gas, phase micro chemical systems, Chem. Eng. Sci. 55 (2000) 3065-3075.

[5] S. Yu, T.A. Ameel, Slip flow heat transfer in rectangular microchannels, Int. J. Heat Mass Transfer 44 (2001) 42254234.

[6] G. Tunc, Y. Bayazitoglu, Heat transfer in rectangular micro channels, Int. J. Heat Mass Transfer 45 (2002) 765773.

[7] J.-M. Li, B.-X. Wang, X.-F Peng, 'Wall-adjacent layer' analysis for developed-flow laminar heat transfer of gases in microchannels, Int. J. Heat Mass Transfer 43 (2000) 839-847.

[8] G.L. Morini, Analytical determination of the temperature distribution and Nusselt numbers in rectangular ducts with constant axial heat flux, Int. J. Heat Mass Transfer 43 (2000) 741-755.

[9] R.K. Shah, A.L. London, Laminar Flow Forced Convection in Ducts Advances in Heat Transfer, Academic Press, 1978.

[10] W.M. Rohsenow, J.P. Hartnett, E.N. Ganic, Handbook of Heat Transfer Fundamentals, second ed., McGraw-Hill, 1985.

[11] A.G. Fedorov, R. Viskanta, Thee-dimensional conjugate heat transfer in the microchannel heat sink for electronic packaging, Int. J. Heat Mass Transfer 43 (2000) 399415.

[12] Fluent Incorporated. FLUENT 5 User's Guide Volume, 1998.

[13] N. Gupta, V. Balakotaiah, Heat and mass transfer coefficients in catalytic monoliths, Chem. Eng. Sci. 56 (2001) 4771-4786.

[14] P.T. Boggs, R.H. Byrd, J.E. Rogers, R.B. Schnabel, ODRPACK Version 2.01 Software for Weighted Orthogonal Distance Regression, National Institute of Standards and Technology, Gaithersburg, 1992.

[15] W. Qu, I. Mudawar, Analysis of three-dimensional heat transfer in micro-channel heat sinks, Int. J. Heat Mass Transfer 45 (2002) 3973-3985. 
[16] D.A. Hickman, L.D. Schmidt, Steps in $\mathrm{CH}_{4}$ oxidation on Pt and rh surfaces: high temperature reactor simulations, AIChE J. 39 (7) (1993) 1164-1177.

[17] R.B. Bird, W.E. Stewart, E.N. Lightfoot, Transport Phenomena, John Wiley and Sons, 2002.

[18] T.H. Chilton, A.P. Colburn, Mass transfer adsorption coefficients, Ind. Eng. Chem. 26 (1934) 1183-1187.
[19] J.R. Welty, C.E. Wicks, R.E. Wilson, Fundamentals of Momentum, Heat, and Mass Transfer, third ed., John Wiley and Sons, 1984.

[20] F.W. Schmidt, M.E. Newell, Heat transfer in fully developed laminar flow through rectangular and isoceles triangular ducts, Int. J. Heat Mass Transfer 10 (1967) 1121-1123. 